\title{
SELETIVIDADE DE HERBICIDAS À GRAMA BATATAIS E SUA RELAÇÃO COM AS CARACTERÍSTICAS ANATÔMICAS FOLIARES
}

\author{
Renata Pereira Marques ${ }^{1}$, Dagoberto Martins, Roberto Antonio Rodella ${ }^{2}$, Saulo Ítalo de Almeida Costa ${ }^{3}$ \\ ${ }^{1}$ Instituto Federal Goiano, Curso de Agronomia, GO. ${ }^{2}$ Universidade Estadual Paulista - UNESP, Faculdades de Ciências \\ Agrárias e Veterinária - FCA9V, Jaboticabal, SP. ${ }^{3}$ Universidade Estadual Paulista - UNESP, Instituto de Biociências de \\ Botucatu - IBB, Botucatu, SP. E-mail: r.pmarques@yahoo.com.br
}

\section{RESUMO}

Objetivou-se avaliar a seletividade de herbicidas aplicados em pós-emergência sobre Paspalum notatum e relacioná-la com os caracteres da anatomia foliar. Os herbicidas $\left(\mathrm{g} \mathrm{ha}^{-1}\right)$ testados foram: bentazon (720), nicosulfuron (50), halosulfuron (112,5), oxadiazon (875) e 2,4-D (698) e um tratamento controle sem herbicidas. A fitointoxicação foi avaliada dos 7 aos 35 dias após a aplicação dos herbicidas (DAA). Para a análise anatômica foliar coletou-se folhas aos 35 DAA. Avaliou-se a \% fitointoxicação, a altura e a massa seca da grama pela análise de variância pelo teste $\mathrm{F}$ e pelo teste de Tukey a $5 \%$. Os valores dos caracteres anatômicos foram submetidos ao teste de análise de agrupamento. Os herbicidas bentazon, nicosulfuron, halosulfuron, oxadiazon e 2,4-D causaram injúrias (máximo de 0,5, 33,0, 17,5, 27,25 e 3,5\%, respectivamente) e dissiparam-se até os $35 \mathrm{DAA}$, exceto os sintomas causados pelo nicosulfuron que nesse período de avaliação ainda apresentava $29 \%$ de injúria. Apenas o 2,4-D não afetou a altura de plantas. Não foram observadas diferenças entre os tratamentos quanto à massa seca das plantas. A Análise de Agrupamento resultou na formação de dois grupos distintos, sendo que o primeiro grupo formou-se pelo tratamento controle, bentazon, halosulfuron e 2,4-D; o segundo grupo pelo nicosulfuron e oxadiazon. Nas plantas tratadas com nicosulfuron observou-se redução na \% de parênquima, aumento na espessura da folha e na porcentagem de feixes vasculares; já com o oxadiazon observou-se redução da espessura da folha e na porcentagem de feixes vasculares e aumentou a epiderme abaxial e a $\%$ da bainha do feixe na região da asa. As porcentagens da epiderme adaxial e abaxial, da bainha do feixe, do feixe vascular e do parênquima conferiram a seletividade dessa espécie aos herbicidas testados. Os herbicidas que constituíram o segundo grupo foram os menos seletivos à espécie.

Palavras-chave: análise de agrupamento; anatomia vegetal; gramados; Paspalum notatum

\section{HERBICIDE SELECTIVITY TO BATATAIS GRASS AND ITS RELATION TO THE LEAF ANATOMICAL CHARACTERISTICS}

\begin{abstract}
The objective of this study was to evaluate the selectivity of herbicides applied in post-emergence on Paspalum notatum $\mathrm{L}$. and to relate it to the characters of the leaf anatomy. The herbicides $\left(\mathrm{g} \mathrm{ha}^{-1}\right)$ tested were: bentazon (720), nicosulfuron (50), halosulfuron (112.5), oxadiazon (875) and 2.4-D (698) and a control treatment without herbicides. The phytotoxicity was evaluated from 7 to 35 days after herbicide application (DAA). Leaf anatomy was collected at 35 DAA. The percent phytotoxification, height and dry mass of the grass were evaluated by analysis of variance by the $\mathrm{F}$ test and by the Tukey test at $5 \%$. The values of the anatomical characters were submitted to the cluster analysis test. The herbicides bentazon, nicosulfuron, halosulfuron, oxadiazon and 2,4-D caused injuries (maximum of 0.5, 33.0, 17.5, 27.25 and $3.5 \%$, respectively) and dissipated up to $35 \mathrm{DAA}$, except the symptoms caused by nicosulfuron, which in this evaluation period still presented $29 \%$ of injury. Only $2.4-\mathrm{D}$ did not affect plant height. No differences were observed between the treatments regarding the dry mass of the plants. The cluster analysis test resulted in the formation of two distinct groups, the first group being formed by the control treatment, bentazon, halosulfuron and 2,4-D; the second group by nicosulfuron and oxadiazon. In plants treated with nicosulfuron, there was a reduction in parenchyma\%, increase in leaf thickness and percentage of vascular bundles; with oxadiazon, a reduction in leaf thickness and in the percentage of vascular bundles was observed and the abaxial epidermis and \% of the sheath of the bundle in the wing region were increased.
\end{abstract}


The percentages of adaxial and abaxial epidermis, bundle sheath, vascular bundle and parenchyma confer the selectivity of this species to the tested herbicides. The herbicides that constituted the second group were the least selective to the species.

Key words: cluster analysis; lawns; Paspalum notatum; plant anatomy

\section{INTRODUÇÃO}

Dentro da família Poaceae existem cerca de 10.000 espécies, dessas, apenas algumas dezenas estão aptas formar um gramado denso para a utilização na prática de esportes ou como ornamental. Paspalum notatum é uma dessas espécies e está amplamente distribuída no Brasil e tem assumido importante destaque pelo seu valor estético e funcionalidade. Além disso, é pouco exigente em nutrientes, baixa necessidade de manutenção, boa tolerância ao pisoteio e ao frio e possui aparência atrativa (MACIEL et al., 2010; STEINER et al., 2017). Toda essa rusticidade estimula a utilização e comercialização da espécie para compor áreas de gramado para diversos usos, no entanto, desencadeia pouca dedicação no manejo dessa espécie, o que culmina no aparecimento de plantas daninhas, que comprometem o valor estético e usabilidade dessas áreas (MARQUES et al., 2016; McELROY; MARTINS, 2013). O uso de herbicidas para o manejo de plantas daninhas em gramados ainda é o método mais utilizado.

De acordo com Andrei (2013) não existe nenhum herbicida registrado para o controle de plantas daninhas em áreas de gramado, dificultando o manejo de infestantes na produção e manutenção dos gramados.

Alguns estudos sobre a seletividade de herbicidas para gramados foram realizados no Brasil (COSTA et al., 2010; FREITAS et al., 2003; CHRISTOFFOLETI; ARANDA, 2001), no entanto, trabalhos que relacionam a seletividade de herbicidas com a anatomia foliar de espécies de gramas ainda não foram realizados. Em contrapartida, trabalhos como os realizados por Costa et al. (2012), Ferreira et al. $(2002,2003)$ e Monquero et al. (2005) fazem esse tipo de relação entre a anatomia de plantas e sua tolerância diferencial aos herbicidas. Esses autores observaram que alterações nos mais diversos tecidos que influenciam na absorção e translocação dos herbicidas e isso pode variar de acordo com a espécies estudadas, de modo que porcentagem da epiderme abaxial, porcentagem da endoderme, porcentagem de feixe vascular, porcentagem de esclerênquima e espessura foliar, grande espessura da cutícula da face adaxial e da cutícula, elevado teor de cera epicuticular e alta densidade tricomática foram os principais obstáculos potenciais detectados à penetração de herbicidas.

$\mathrm{Na}$ escolha dos herbicidas para o uso em gramado, ressalta-se que produtos seletivos a culturas monocotiledôneas e eficazes no manejo de plantas daninhas de folhas largas e estreitas podem apresentar elevado potencial de uso no controle das infestantes em gramados (GLENN et al., 2015).

As moléculas bentazon, nicosulfuron, halosulfuron, oxadiazon e 2,4-D são eficientes no controle de plantas daninhas e em países como os EUA são empregados em áreas de gramados por também serem seletivas a espécies de gramas (GIMENEZ et al., 1998; DERR, 2012; PARKER, 2014; SIDHU et al., 2014). A maioria das informações que circulam no Brasil é oriunda de experiências de profissionais do setor e/ou adaptações de publicações americanas, divulgadas informalmente e sem respaldo científico sobre aspectos como seletividade e eficácia de herbicidas (MACIEL, 2013).

A espécie de grama $P$. notatum é bastante sensível à competição imposta pelas plantas daninhas e a disponibilidade de moléculas herbicidas seletivas pode facilitar o manejo dessa interferência. Adicionalmente, o conhecimento das características anatômicas foliares desta espécie de grama contribui para o entendimento sobre a seletividade de herbicidas e torna-se uma ferramenta muito útil na descrição de sintomas de fitointoxicação. Dessa maneira, o objetivo geral deste trabalho foi avaliar a seletividade dos herbicidas aplicados em pós-emergência sobre essa espécie e relacioná-la com os caracteres anatômicos foliares.

\section{MATERIAL E MÉTODOS}

Este estudo foi realizado utilizando-se uma área de gramado formada por Paspalum notatum L. (grama Batatais) com 48 meses de idade. O gramado foi submetido a aplicação de 
herbicidas em pós-emergência. Antes da aplicação dos herbicidas, o gramado foi aparado a uma altura de $3 \mathrm{~cm}$ e uma semana após à poda realizaram-se as aplicações dos tratamentos. Durante a aplicação, as parcelas foram protegidas lateralmente com biombos de lona plástica com o objetivo de evitar deriva de calda pulverizada para as parcelas adjacentes.

O delineamento experimental utilizado foi o de blocos casualizados (DBC), constituído por 6 tratamentos com quatro repetições. As parcelas experimentais apresentavam a dimensão de $2 \mathrm{~m}$ de largura por $2 \mathrm{~m}$ de comprimento, totalizando uma área de $4 \mathrm{~m}^{2}$.

Os tratamentos químicos utilizados foram bentazon $\left(720 \mathrm{~g} \mathrm{ha}^{-1}\right)$, nicosulfuron ( $50 \mathrm{~g} \mathrm{ha}$ $\left.{ }^{1}\right)$, halosulfuron $\left(112,5 \mathrm{~g} \mathrm{ha}^{-1}\right)$, oxadiazon (875 $\mathrm{g}$ ha $\left.{ }^{1}\right)$ e 2,4-D (698 $\left.\mathrm{g} \mathrm{ha}^{-1}\right)$, além de um tratamento controle sem aplicação. Os herbicidas foram aplicados em pós-emergência, utilizando-se um pulverizador costal, pressurizado por $\mathrm{CO}_{2}$ e equipado com um reservatório de 2 L. O equipamento foi regulado para proporcionar um consumo de calda de $250 \mathrm{~L} \mathrm{ha}^{-1}$. A barra de aplicação foi equipada com cinco pontas do tipo jato plano "Teejet" DG 11002 distanciados $50 \mathrm{~cm}$ entre si, a uma pressão de trabalho de $25 \mathrm{lb}$ pol- ${ }^{2}$.

As avaliações de fitotoxidade em $P$. notatum foram realizadas semanalmente, dos 7 aos 35 dias após a aplicação dos herbicidas (DAA), até o desaparecimento dos sintomas. Para as avaliações de fitotoxidade utilizou-se uma escala percentual de notas visuais, no qual 0 (zero) corresponde a nenhuma injúria demonstrada pelas plantas e 100 (cem) à morte das plantas. Os parâmetros utilizados para o estabelecimento das notas foram: acúmulo de biomassa, inibição do crescimento, quantidade e uniformidade das injúrias e capacidade de rebrota das plantas.

A altura das plantas (do solo até o ápice da maior folha) foi mensurada aos 14 e 28 DAA com o auxílio de uma régua graduada em centímetros, simultaneamente às avaliações de fitointoxicação.

A massa seca total produzida pelos tratamentos foi determinada no final do período de condução do experimento, aos 35 DAA. Assim, coletou-se a massa vegetal de $1 \mathrm{~m}^{2}$ de parcela e após a secagem em estufa de circulação forçada de ar a 65 ㄷ, o material foi medido em balança de precisão.

Para se proceder à análise anatômica foliar de $P$. notatum, o material foliar foi amostrado ao acaso na parcela, coletando-se as folhas inteiramente expandidas aos 35 DAA.

Foram amostradas as porções do terço médio do limbo foliar, fixando-as em FAA 50 (formaldeído + ácido acético glacial + álcool 50\%), durante 48 horas, sendo, posteriormente, conservadas em álcool 70\% (JOHANSEN, 1940), utilizando-se quatro repetições.

Após a fixação, as amostras foliares foram desidratadas em série etílica ascendente e, em seguida, infiltradas em resina glicolmetacrilato, seguindo-se a técnica de Gerrits (1991). Foram realizados cortes transversais com espessuras de 4 a $8 \mu \mathrm{m}$ utilizando micrótomo rotatório, sendo os cortes submetidos à coloração com Azul de Toluidina 0,05\% (O'BRIEN et al., 1964) e, em seguida, montados em resina sintética "Permount".

Posteriormente, foram feitas as observações microscópicas das estruturas anatômicas de acordo com Metcalfe (1960). As regiões analisadas foram: nervura central (quilha) e a região compreendida entre a nervura central e a margem do limbo (asa). As imagens foram obtidas utilizando-se um fotomicroscópio da marca Olympus acoplado a uma câmera digital. Os limites $e$ os contornos dos tecidos foram mensurados pelo software Cell^B Olympus.

A quantificação das estruturas anatômicas presentes no limbo foliar foi obtida a partir da proporção dos caracteres quantitativos das regiões da quilha (nervura central) e da asa (região compreendida entre a nervura central e a margem do limbo). Quantificou-se nessas regiões a porcentagem (\%) de epiderme das faces adaxial e abaxial, feixe vascular, bainha do feixe vascular, esclerênquima e parênquima em relação à área total do tecido mensurado na região avaliada. Mensurou-se também na região da asa a distância entre os feixes, a espessura foliar e o número de feixes vasculares presentes na estrutura foliar, contando-se o primeiro feixe da quilha até o segundo maior feixe existente ao longo da asa.

Os valores médios dos 15 caracteres anatômicos foliares quantitativos da região da quilha e da asa de $P$. notatum obtidos aos 35 DAA foram submetidos à análise multivariada, compreendendo o teste estatístico de Análise de Agrupamento.

A Análise de Agrupamento foi realizada com os dados transformados em porcentagem, empregando-se a Distância Euclidiana Média para o conjunto de indicadores, utilizando-se o algoritmo UPGMA (unweighted pair group method 
with arithmetic average), com a finalidade de agrupar as espécies de gramas e os tratamentos de acordo com o seu grau de similaridade, sendo o resultado desta análise apresentado na forma de dendrograma. O programa estatístico utilizado na análise multivariada foi o NTSYS 1.7.

Os resultados obtidos para porcentagem de fitointoxicação, altura de plantas e de massa seca da parte aérea foram submetidos à análise de variância pelo teste $F$, e as médias dos tratamentos foram comparadas pelo teste de Tukey a $5 \%(p \leq 0,05)$ de probabilidade, sendo os dados de fitointoxicação (porcentagem) de $P$. notatum transformados em arcsen $\sqrt{x} / 100$ e os dados de pesagem foram transformados em $\sqrt{ } x+1$.

\section{RESULTADOS E DISCUSSÃO}

A Tabela 1 apresenta os resultados da aplicação dos diferentes herbicidas estudados sobre $P$. notatum. Foi possível verificar que aos 7 DAA todos os herbicidas testados (com exceção do herbicida bentazon) causaram injúrias (descoloração e amarelecimento) ao gramado. Os herbicidas nicosulfuron e oxadiazon apresentaram danos acima de $25 \%$. Os sintomas de injúrias proporcionados pelos herbicidas bentazon, halosulfuron, oxadiazon e 2,4-D dissiparam-se até os 35 DAA.

Tabela 1. Sintomas de intoxicação (\%) observados nas plantas de Paspalum notatum submetidas à aplicação dos herbicidas. Botucatu-SP, 2009.

\begin{tabular}{lcllll}
\hline \multirow{2}{*}{ Tratamentos } & $\begin{array}{c}\text { Doses } \\
\text { g ha- }{ }^{1}\end{array}$ & \multicolumn{5}{c}{ Dias após a aplicação dos herbicidas } \\
\cline { 2 - 6 } controle & - & $0,00(0,00) \mathrm{d}$ & $0,00(0,00)$ e & $0,00(0,00)$ & $\mathrm{b}$ \\
bentazon & 720 & $0,50(3,00) \mathrm{d}$ & $0,00(0,00)$ e & $0,00(0,00) \mathrm{b}$ \\
nicosulfuron & 50 & $33,00(34,75) \mathrm{a}$ & $31,25(33,75) \mathrm{a}$ & $29,00(32,50) \mathrm{a}$ \\
halosulfuron & 112,5 & $17,50(24,75) \mathrm{b}$ & $7,50(15,50) \mathrm{c}$ & $0,00(0,00)$ & $\mathrm{b}$ \\
oxadiazon & 875 & $27,25(31,25) \mathrm{a}$ & $14,00(21,75) \mathrm{b}$ & $2,00(5,75)$ & $\mathrm{b}$ \\
2,4-D & 698 & $3,50(10,50) \mathrm{c}$ & $2,50(9,00) \mathrm{d}$ & $0,00(0,00)$ & $\mathrm{b}$ \\
\hline F tratamento & & $135,66^{* *}$ & $213,34^{* *}$ & $67,73^{* *}$ & \\
C.V. (\%) & & 14,7 & 13,5 & 49,6 & \\
Erro Padrão & & 1,28 & 0,90 & 1,58 & \\
D.M.S & & 5,74 & 4,05 & 7,10 & \\
\hline
\end{tabular}

Médias seguidas de mesma letra na coluna não diferem estatisticamente entre si pelo Teste de Tukey $(p \leq 0,05)$ Os dados de porcentagem (\%) foram transformados em arco seno $\sqrt{ } \mathrm{x} / 100$ e seus valores estão entre parênteses. -**: significativo a $1 \%$ de probabilidade

Costa et al. (2010) estudaram os efeitos de diferentes herbicidas sobre $P$. notatum. Os autores relataram intoxicações severas nesta espécie de grama com aplicações de nicosulfuron, superiores a $20 \%$ de injúrias nas plantas utilizando a dose de $125 \mathrm{~g} \mathrm{ha}^{-1}$. Além disso, consideraram também que os herbicidas bentazon e 2,4-D potencialmente seletivos às plantas de grama Batatais, nas doses $600 \mathrm{~g} \mathrm{ha}^{-1} \mathrm{e}$ $720 \mathrm{~g} \mathrm{ha}^{-1}$, respectivamente.

Desta forma, dentre os herbicidas testados, o nicosulfuron foi o menos seletivo a esta espécie de grama, uma vez que, os sintomas de intoxicação (29\%) ainda estavam presentes aos 35 DAA. Pode-se observar neste período que as plantas de $P$. notatum submetidas a aplicação do herbicida oxadiazon ainda apresentavam leves sintomas de intoxicação.

$\mathrm{Na}$ altura de plantas (Tabela 2) ocorreram diferenças estatísticas aos 21 e 35 DAA. Em todos os períodos de avaliação, as plantas submetidas à aplicação do herbicida nicosulfuron apresentaram as menores alturas. Aos 35 DAA o 2,4-D foi o único herbicida que não afetou a altura de plantas. Aos 21 DAA o efeito dos herbicidas bentazon, halosulfuron e oxadiazon foram semelhantes. 
Tabela 2. Altura de plantas de Paspalum notatum submetidas à aplicação de herbicidas. Botucatu-SP, 2009.

\begin{tabular}{lcccc}
\hline \multirow{2}{*}{ Tratamentos } & Doses & \multicolumn{3}{c}{ Altura de plantas (cm) } \\
\cline { 3 - 5 } & $\mathrm{g} \mathrm{ha}^{-1}$ & \multicolumn{3}{c}{ Dias após a aplicação dos herbicidas } \\
\cline { 3 - 5 } & & 5,37 & $6,15 \mathrm{a}$ & 75 \\
\hline controle & - & 5,32 & $5,25 \mathrm{~b}$ & $7,17 \mathrm{a}$ \\
bentazon & 720 & 5,20 & $4,77 \mathrm{c}$ & $5,07 \mathrm{~b}$ \\
nicosulfuron & 50 & 5,02 & $5,37 \mathrm{~b}$ & $7,17 \mathrm{a}$ \\
halosulfuron & 112,5 & 5,22 & $5,45 \mathrm{~b}$ & $7,15 \mathrm{a}$ \\
oxadiazon & 875 & 5,27 & $5,95 \mathrm{a}$ & $7,85 \mathrm{a}$ \\
2,4-D & 698 & $1,22^{\text {ns }}$ & $19,08^{* *}$ & $10,88^{* *}$ \\
\hline F tratamento & & 13,3 & 13,1 & 26,8 \\
C.V. (\%) & & 0,11 & 0,11 & 0,30 \\
Erro Padrão & & 0,45 & 0,46 & 1,20 \\
D.M.S & & &
\end{tabular}

Médias seguidas de mesma letra na coluna não diferem estatisticamente entre si pelo Teste de Tukey $(p \leq 0,05)$

-**: significativo a $1 \%$ de probabilidade

- •ns: não significativo

Quanto à massa seca (Tabela 3) não houve diferença nos valores de massa seca da parte aérea das plantas de $P$. notatum, de modo a confirmar os resultados das avaliações visuais de fitointoxicação, ainda que as plantas de $P$. notatum submetidas ao nicosulfuron e oxadiazon tenham apresentado maiores injúrias, ao final das avaliações o acúmulo de biomassa igualou-se inclusive ao tratamento controle.

Tabela 3. Massa seca de plantas de Paspalum notatum submetidas a aplicação de herbicidas. Botucatu-SP, 2009.

\begin{tabular}{lcc}
\hline \multicolumn{1}{c}{ Tratamentos } & $\begin{array}{c}\text { Doses } \\
\text { gi.a./e.a ha }{ }^{1}\end{array}$ & Massa seca (gramas) \\
\hline controle & - & $6,07(3,00)$ \\
bentazon & 720 & $5,53(2,75)$ \\
nicosulfuron & 50 & $7,74(3,00)$ \\
halosulfuron & 112,5 & $5,58(2,50)$ \\
oxadiazon & 875 & $6,19(2,75)$ \\
2,4-D & 698 & $6,61(2,50)$ \\
\hline F tratamento & & $0,65 \mathrm{~ns}$ \\
C.V. (\%) & & 20,1 \\
Erro Padrão & & 0,28 \\
D.M.S & & 1,24 \\
\hline Os.asde
\end{tabular}

Os dados de pesagem foram transformados em $v x+1,0$ e seus valores estão entre parênteses ( )

• ns: não significativo

Costa et al. (2010) consideram que após a metabolização dos herbicidas, pode haver rápida disponibilização das reservas de energia para o restabelecimento do desenvolvimento normal da grama, caracterizando um efeito compensatório no acúmulo de biomassa após o desaparecimento das injúrias e além disso, ressaltam a importância da realização de mais estudos para identificar e descrever os mecanismos fisiológicos envolvidos nos processos de desintoxicação dos herbicidas em plantas.

O limbo foliar em secção transversal de $P$.

notatum (Figura 1) caracterizou-se por apresentar quilha pouco acentuada e com epiderme unisseriada em ambas as faces e revestidas por cutícula, sendo esta mais espessa na face adaxial. A face abaxial da epiderme é mais lignificada. Na face adaxial localizam-se as células buliformes organizadas em grupos de 5 a 7 células com o formato de leque na epiderme da face adaxial. Observaram-se também calotas de esclerênquima localizadas nas porções adaxial e abaxial do feixe vascular central, apresentando maior número de camadas na porção abaxial do feixe, próximo ao floema. Na porção adaxial estão presentes células arredondadas de 
parênquima fundamental. 0 parênquima clorofiliano é homogêneo com clorênquima radiado, com células mesofílicas dispostas em coroa ao redor de cada feixe vascular, caracterizando a estrutura "Kranz" e comprovando a anatomia $\mathrm{C} 4$ tal como observado por Scheffer-Basso (2002) e Ribeiro et al. (2006). Os feixes vasculares apresentam elementos de xilema e floema e a bainha do feixe vascular é simples e contínua, formada de células parenquimáticas providas de cloroplastos.

Figura 1. Secções transversais do limbo foliar de Paspalum notatum. Bf: Bainha do Feixe Vascular. Cb: Células Buliformes. EAb: Epiderme da Face Abaxial. EAd: Epiderme da Face Adaxial. Esc: Esclerênquima. Fl: Floema. Par: Parênquima. Pf: Parênquima fundamental. Xi: Xilema. A,F: região da quilha (nervura central). B,C,D,E: região da asa (porção entre a nervura central e a margem do limbo). Barra $=100 \mu \mathrm{m}(\mathbf{A}, \mathbf{E}, \mathbf{F})$. Barra $=50 \mu \mathrm{m}(\mathbf{B}, \mathbf{C}, \mathbf{D})$. A (controle); $\mathbf{B}$ (bentazon); C (nicosulfuron); D (halosulfuron); E (oxadiazon) F (2,4-D). Botucatu-SP, 2009.

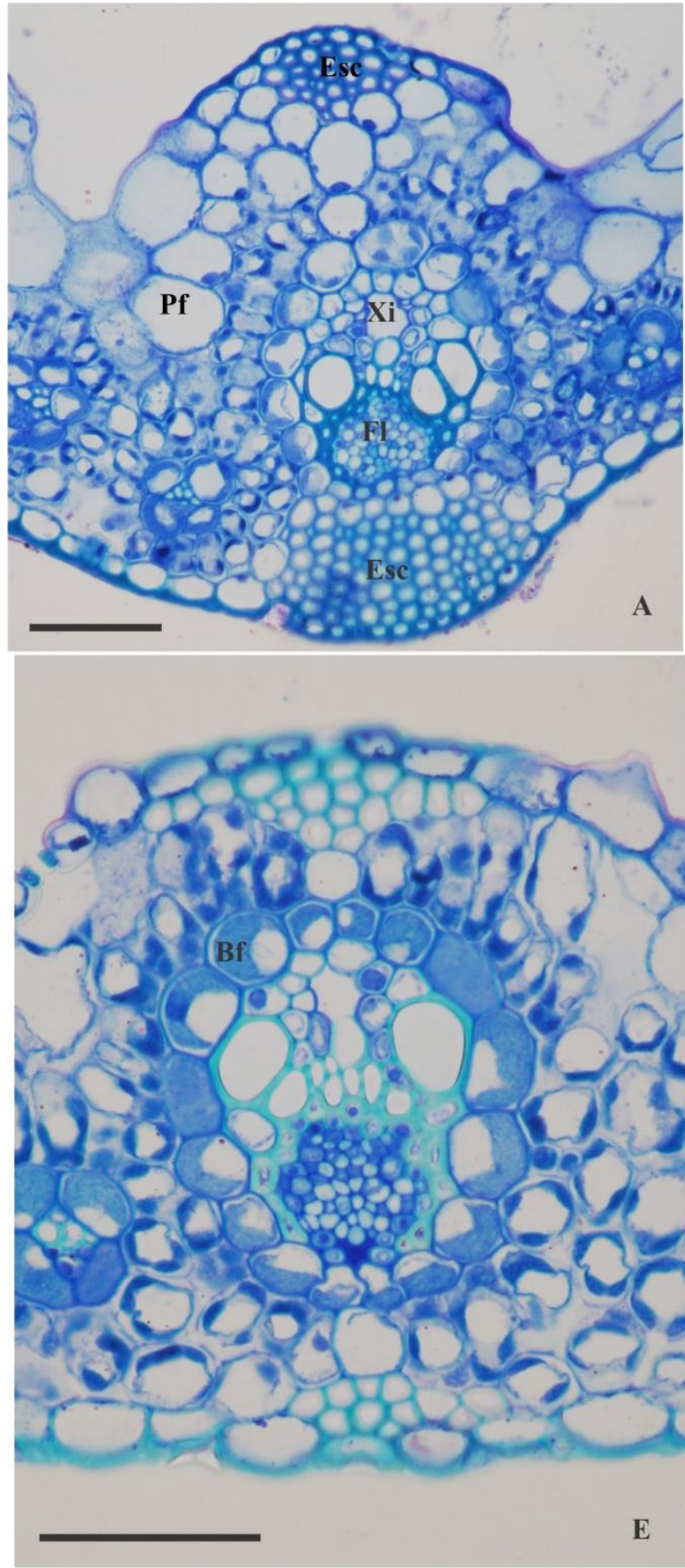

A região compreendida entre a nervura central e a margem do limbo foliar (asa) de $P$.
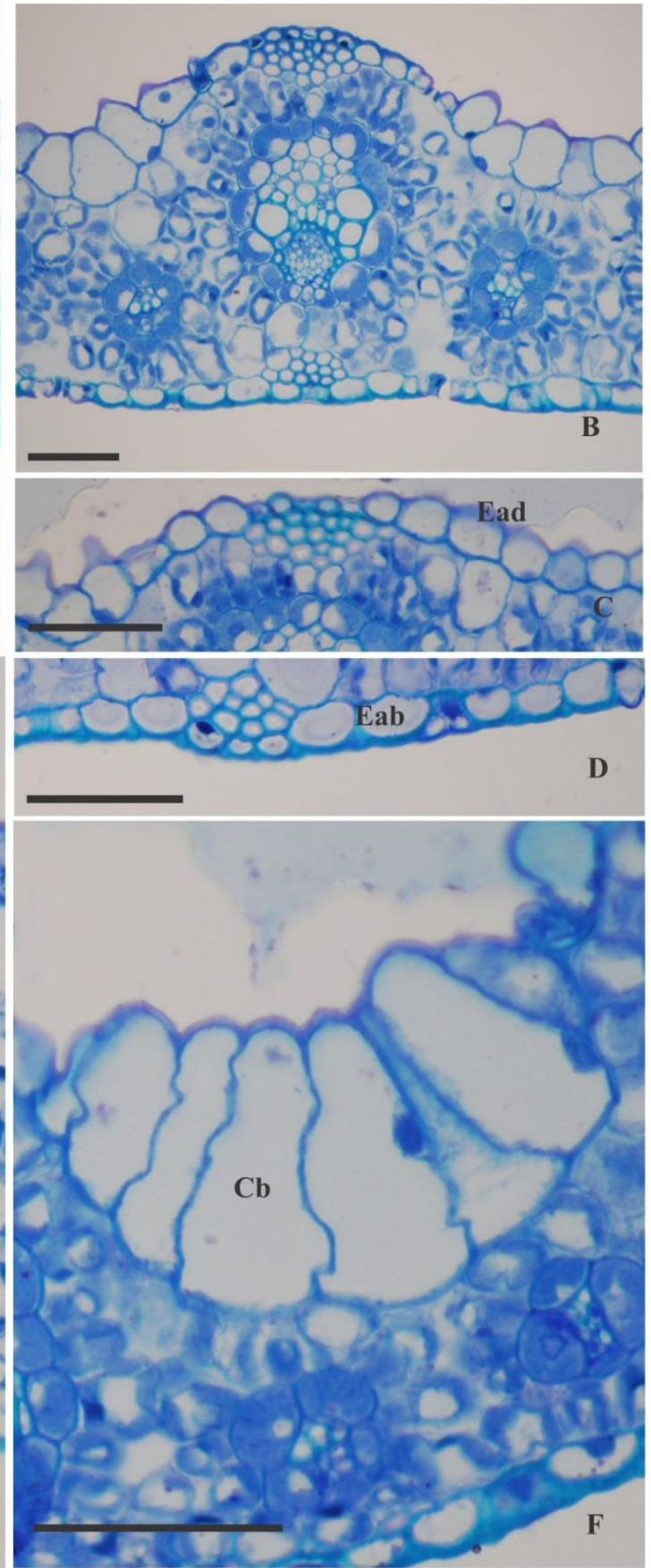

notatum apresenta as mesmas características observadas para a região da quilha, no entanto, 
pode se observar os estômatos em ambas as faces (espécie anfiestomática) e as calotas subepidérmicas de esclerênquima localizadas somente nos feixes vasculares de maior tamanho.

Não foram observadas alterações visuais dos caracteres anatômicos foliares de $P$. notatum causada pela aplicação dos herbicidas. No entanto, quando analisados quantitativamente, esses caracteres indicaram alterações causadas pela aplicação de herbicidas. Morô e Damião Filho (1999) ao relacionarem a seletividade do herbicida nicosulfuron com alterações morfoanatômicas em plantas de milho observaram aumento considerável no número, tamanho e forma das células buliformes em ambas as faces da lâmina foliar, com desaparecimento quase total de células epidérmicas fundamentais.

A Figura 2 apresenta o dendrograma resultante da análise de agrupamento dos valores médios dos caracteres anatômicos foliares de $P$. notatum. Foi possível observar que aos 35 DAA resultou na formação de dois grupos distintos, sendo que o primeiro grupo ao nível de 0,20 na escala de distância de similaridade formou-se pelo tratamento controle, com os herbicidas bentazon, halosulfuron e 2,4-D; o segundo grupo foi representado pelos herbicidas nicosulfuron e oxadiazon.

Os herbicidas que constituem o primeiro grupo não causaram alterações nos tecidos foliares, não diferindo do tratamento controle, já nas plantas tratadas com nicosulfuron observouse redução na \% de parênquima, aumento na espessura da folha e na porcentagem de feixes vasculares; com o oxadiazon causou alterações no limbo foliar ao reduzir a espessura da folha e a porcentagem de feixes vasculares e aumentou a epiderme abaxial e a \% da bainha do feixe. Esses resultados indicam que a menor seletividade dos herbicidas do grupo 2 deve-se à alteração dos tecidos supracitados, indicando, portanto, que eles estão relacionados à menor ou menor tolerância de $P$. notatum aos herbicidas deste grupo, como os descritos na Tabela 1, indicando que esses herbicidas foram menos seletivos às plantas de $P$. notatum.

Figura 2. Dendrograma resultante da Análise de Agrupamento dos 15 caracteres anatômicos foliares quantitativos, utilizando-se a Distância Euclidiana Média entre os herbicidas aplicados sobre Paspalum notatum aos 35 dias após a aplicação dos herbicidas. Botucatu-SP, 2009.
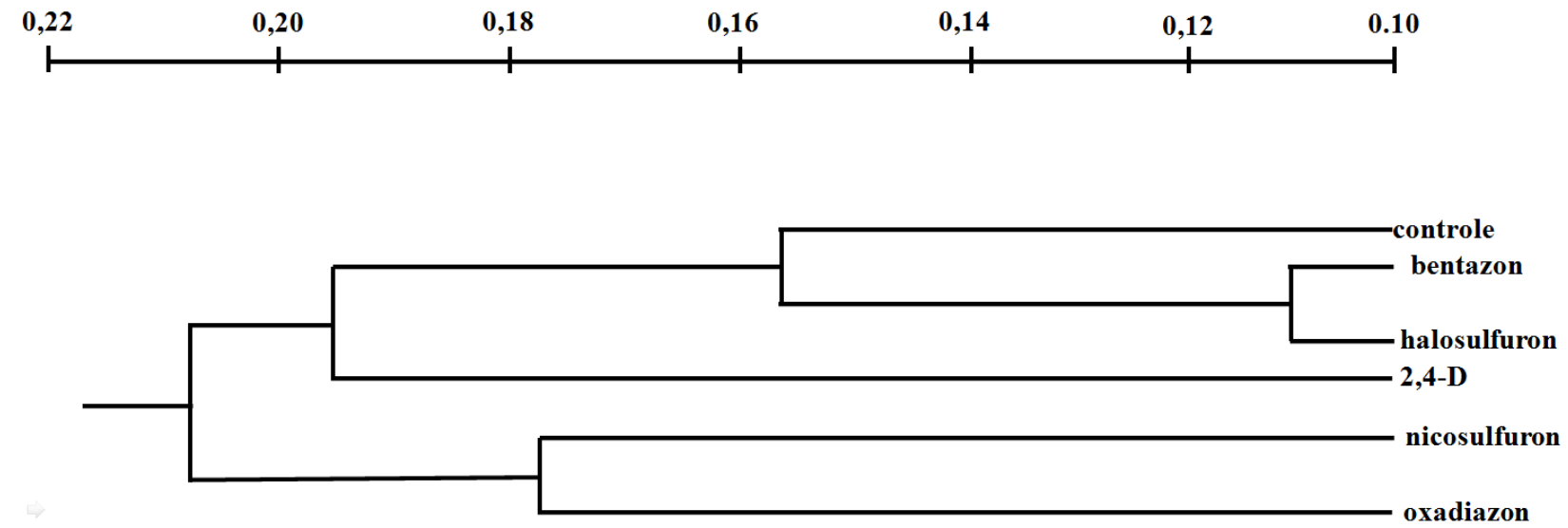

\section{CONCLUSÕES}

Conclui-se que dentre os herbicidas testados, o nicosulfuron foi o menos seletivo a esta espécie de grama. No que diz respeito à relação entre a seletividade destes herbicidas e a anatomia foliar não foram observados alterações visuais nos caracteres anatômicos foliares de $P$. notatum causada pela aplicação dos herbicidas bentazon, nicosulfuron, halosulfuron, oxadiazon e 2,4-D. Todavia, quando analisados quantitativamente, conclui-se que esses caracteres sofreram alterações pela aplicação dos herbicidas, de forma que a \% de parênquima, epiderme abaxial e de feixes vasculares, a espessura da folha estão diretamente relacionados com a seletividade de herbicidas em P. notatum.

\section{AGRADECIMENTOS}

Os autores gostariam de agradecer o Conselho Nacional de Desenvolvimento Científico e Tecnológico, CNPq Processo $n^{\circ}$ 140597/2009-3 pelo suporte financeiro e à Universidade Estadual 
Paulista Júlio de Mesquita Filho, UNESP, pelo uso de seus laboratórios.

\section{REFERÊNCIAS}

ANDREI, E. Compêndio de defensivos agrícolas. São Paulo: Ed. Andrei, 2013.

CHRISTOFFOLETI, P. J. Seletividade de herbicidas a cinco tipos de gramas. Planta Daninha, v. 19, p. 273-278, 2001. https://doi.org/10.1590/S0100$\underline{83582001000200016 .}$.

COSTA, N. V. MARTINS, D.; RODRIGUES, A. C. P.; CARDOSO, L. A. Seletividade de herbicidas aplicados na Grama Batatais e na Grama São Carlos. Planta Daninha, v.28, p.365-374, 2010. https://doi.org/10.1590/S0100-

83582010000200016.

COSTA, N. V.; MARTINS, D.; RODELLA, R. A.; RODRIGUES-COSTA, A. C. P. Alterações anatômicas foliares em plantas de Brachiaria subquadripara submetidas à aplicação de herbicidas. Planta Daninha, v.30, p.253-261, $2012 . \quad$ https://doi.org/10.1590/S010083582003000200012.

DERR, J.F. Broadleaf Weed Control with Sulfonylurea Herbicides in Cool-Season Turfgrass. Weed Technology, v.26, p.582-586, 2012. http://www.bioone.org/doi/full/10.1614/WT-D-

11-00166.1. https://doi.org/10.1614/WT-D-1100166.1

FERREIRA, E. A.; PROCÓPIO, S. O.; SILVA, E. A. M.; SILVA, A. A.; RUFINO, R. J. N. Estudos anatômicos de folhas de espécies de plantas daninhas. II Bidens pilosa, Emilia sonchifolia, Ageratum conyzoides e Sonchus asper. Planta Daninha, v. 20, n.3, p.327-335, 2002. https://doi.org/10.1590/S0100-

83582002000300001.

FERREIRA, E. A.; PROCÓPIO, S. O.; SILVA, E. A. M.; SILVA, A. A.; RUFINO, R. J. N. Estudos anatômicos de folhas de espécies de plantas daninhas de grande ocorrência no Brasil. IV- Amaranthus deflexus, Amaranthus spinosus, Alternanthera tenella e Euphorbia heterophylla. Planta Daninha, v.21, n.2, p.263-271, 2003. https://doi.org/10.1590/S010083582003000200012 .
FREITAS, F. C. L.; FERREIRA, L. R.; SILVA, A. A.; BARBOSA, J. G.; MIRANDA, G. V.; MACHADO, A. F. L. Eficiência do triclopyr no controle de plantas daninhas em gramado (Paspalum notatum). Planta Daninha, v.21, p.159-164, 2003. https://doi.org/10.1590/S0100$\underline{83582003000100020 .}$.

GERRITS, P. O. The application of glycol methacrylate in histotechnology; some fundamental principles. Department of Anatomy and Embryology. State University of Gröningen, 1991.

GIMENEZ, A. E.; YORK, A. C. WILCUT, J. W.; BATTS R. B. Annual grass control by glyphosate plus, bentazon, chlorimuron, fomesafen or imazethapyr mixtures. Weed Technology, v. 12, p.134-136, 1998.

http://www.jstor.org/stable/3988701.

GLENN B. D. et. al. Evaluation of Alternative Herbicides for Southern Crabgrass (Digitaria ciliaris) Control in St. Augustinegrass. Weed Technology, v.29, p.536-543, 2015. http://dx.doi.org/10.1614/WT-D-14-00094.1.

JOHANSEN, D. A. Plant microtechnique. New York: McGrow-Hill Book, p.523, 1940.

MACIEL, C. D. G.; SAPIA, J. G.; KONDO, P. N.Y.; BENITES, W.L.S.; PEREIRA, J. A. P.; BIRCK, V. E. W.; $S$, A. F. Seletividade e eficácia dos herbicidas Kapina $^{\circledR}$ e Kapina Plus ${ }^{\circledR}$ no controle de tiririca em gramas bermuda e esmeralda. Revista Brasileira de Herbicidas, v.12, n.1, p.39-46, 2013. https://doi.org/10.7824/rbh.v12i1.234

MACIEL, C. D. G.; HAMA, J. T.; SOUZA, J. I. Desenvolvimento inicial de gramado semeado com Paspalum notatum Flügge. Pesquisa Agropecuária Tropical, v. 40, n. 4, p. 547-549, $2010 . \quad$ https://doi.org/10.1590/S198340632010000400022.

MARQUES, R. P.; MARTINS, D.; RODELLA, R. A.; COSTA, S. Í. A.; VITORINO, H. S. Leaf anatomy of emerald grass submitted to quantitative application of herbicides. Semina: Ciências Agrárias, v.37, n.4, p.1767-1777, 2016. https://doi.org/10.1590/s010083582017350100048. 
turfgrass. Planta Daninha, v. 31, n. 2, p. 455-467, 2013. https://doi.org/10.1590/S0100$\underline{83582013000200024}$.

METCALFE, C.R. Anatomy of the Monocotyledons. Oxford: Clarendon Press, 1960.

MONQUERO, P. A.; CURY, J. C.; P. J. CHRISTOFFOLETI. Controle pelo glyphosate e caracterização geral da superfície foliar de Commelina benghalensis, Ipomoea hederifolia, Richardia brasiliensis e Galinsoga parviflora. Planta Daninha, v.23, n.1, p.123-132, 2005. https://doi.org/10.1590/S0100-

83582005000100015.

MORÔ, F. V.; DAMIÃO-FILHO, C. F. Alterações morfo-anatômicas das folhas de milho submetidas à aplicação de nicosulfuron. Planta Daninha, v.17, p.331-337, 1999. https://doi.org/10.1590/S0100-

83581999000300001.

O`BRIEN, T. P.; FEDER, N.; MCCULLY, M. E. Polychmofic staing of plant cellular wall by toluidine blue. Protoplasma, v.59, p.368-373, 1964. https://doi.org/10.1007/BF01248568.

PARKER, E.T. Physiological Basis of Differential Sensitivity of Selected Graminaceous Species to Aminocyclopyrachlor. 2014. 96p. Tese (Doutorado) -Faculty of Auburn University, Department of Agronomy and Soils, 2014.

RIBEIRO, R. V.; LYRA, G. B.; SANTIAGO, A. V. PEREIRA, A. R.; OLIVEIRA, R. F. Diurnal and seasonal patterns of leaf gas exchange in bahiagrass (Paspalum notatum Flügge) growing in a subtropical climate. Grass and Forage Science, v.61, p.293-303, 2006. https://doi.org/10.1111/j.1365-

2494.2006.00533.x.

SCHEFFER-BASSO, S. M. Caracterização Morfofisiológica e Anatômica de Paspalum urvillei (Steudel). Revista Brasileira de Zootecnia, v.31, p.674-1679, 2002. https://doi.org/10.1590/S1516$\underline{35982002000700009}$.

SIDHU, S. S.; YU, J. MCCUlLOUGH, P. E. Nicosulfuron Absorption, Translocation, and Metabolism in Annual Bluegrass and Four Turfgrass Species. Weed Science, v. 62, p.433-
440, 2014. http://www.bioone.org/doi/full/10.1614/WS-D13-00182.1.

STEINER, M. G.; DALL'AGNOL, M.; NABINGER, C.; SCHEFFER-BASSO, S. M.; WEILER, R. L.; SIMIONI, C.; SCHIFINO-WITTMANN, M. T.; MOTTA, É. A.M. Forage potential of native ecotypes of Paspalum notatum and $P$. guenoarum. Anais da Academia Brasileira de Ciências, v.89, n.3, p.1753-1760, 2017. https://doi.org/10.1590/00013765201720160662 .

Recebido para publicação em 20/06/2017

Revisado em 24/10/2017

Aceito em 20/11/2017 